\title{
Guest Editorial: Ignoring the Social and Cultural Context of Bioethics Is Unacceptable
}

\author{
RENÉE C. FOX and JUDITH P. SWAZEY
}

To quote Yogi Berra, writing this editorial is a "déja vu all over again" experience for us. It entails not only collaborating once more as coauthors but also reiterating some of the criticisms and concerns that have figured prominently in virtually all our previous publications about bioethics-most recently in our book Observing Bioethics. ${ }^{1}$

We have repeatedly commented on how restricted and restricting we feel the predominant Western, and especially American, conceptual framework of bioethics is, with what theologian James Gustafson has characterized as its "relatively small set of concepts" autonomy (alternatively known as respect for persons), nonmaleficence, beneficence, and justice, famously articulated in the canonical text Principles of Biomedical Ethics, first published in $1979 .{ }^{3}$ It is a fettering paradigm, we have contended, forged and espoused by some of the field's most prominent practitioners-especially by philosophers trained in the Anglo-American analytic philosophy tradition-that is widely interpreted and utilized by bioethicists in ways that border on intellectual and moral absolutism.

We have recurrently expressed our frustration over how difficult it is to think socially and culturally within the regnant paradigm of bioethics, which in our view minimizes the role of social, cultural, and contextual factors, including social relationships and interaction, in shaping moral precepts, attitudes, and behavior. This propensity, we have said, is reinforced by the field's commitment to identifying and fostering universal ethical principles that constitute a "common morality" (sometimes referred to as "the common morality"), described by philosophers Tom Beauchamp and James Childress as "the set of norms that all morally serious persons ... in all places ... share." ${ }^{4}$ In many instances, we have maintained, the emphasis placed on ethical universalism is accompanied and augmented by an "against relativism" standpoint ${ }^{5}$ that invidiously juxtaposes particularism and universalism in a way that gives moral superiority to universalism and implies that "attend[ing] to the universal" cannot be done "without abandoning the particular." ${ }^{6}$ We have made it plain in our writings that we regard dichotomizing and polarizing universalism and particularism in this fashion as both empirically and morally problematic-all the more so because we are social scientists. In our opinion, it disparages the social and cultural differences that exist within and between societies, negates the importance of recognizing and respecting "otherness" and the many ways of being in the world, and rather ironically masks what is particularistic about bioethical thought by attributing universalism to some of the Western and specifically American culture patterns with which it is imprinted. In this respect, it 


\section{Guest Editorial}

exemplifies what sociologist Pierre Bourdieu has termed "the imperialism of the universal" - "universalizing its own ... particular characteristics by tacitly establishing them in a universal model." 7

The contents of this issue of the Cambridge Quarterly demonstrate that bioethics has progressively spread to numerous Latin American, European, Asian, Near and Middle Eastern, and African societies, carrying with it the key concepts and values and the agenda of biological, medical, and biotechnological questions that characterize bioethics in the United States, where the field originated. In these wide-ranging and diverse societal settings, the persons who are shaping and participating in the development and institutionalization of bioethics are confronted with the challenge of what Aamir Jafarey and Farhat Moazam refer to in their article as "indigenizing" the field. For, as Japanese historian William LaFleur once commented to us, although "bioethics has become international," it has not become "internationalized." 8

What has proven to be the most cross-culturally problematic about the allegedly universalistic form of bioethics is the primacy that its paradigm accords to individualism and individual rights. These are precepts that have deep roots in Western history, culture, and thought; and the kind of respect for the person as a highly autonomous individual that constitutes bioethics' first principle is influenced by a distinctively American conception of the self. In contrast, the social structure, value system, and collective sense of meaning of many societies in the world are centered around the interconnectedness and interdependence of persons, their social ties - especially their family and extended kinship relations-and their associated responsibilities and obligations. What we have characterized as "the resolutely secular orientation" ${ }^{\prime 9}$ of the dominant framework of bioethics is another major source of its incompatibility with the cultural traditions and outlook of the numerous societies to which it has been exported whose conceptions of a "general order of existence" 10 are religiously grounded.

In our publications, we have been openly critical of what we consider to be the "hegemonic thrust" in the way that the U.S. model of bioethics has been exported to other countries and of what we have called the "cultural myopia" that American bioethicists have frequently displayed in failing to recognize some of the American cultural patterns that are embedded in their thought. We have also recurrently called attention to the fact that this cultural "nearsightedness" extends to the deficient attention that U.S. bioethicists have paid to the implications of the extraordinarily multicultural composition of their own society. A spectacular example of the scope of the multiculturalism of American society at this historical juncture, and of the challenges that it poses for the delivery of socially and ethically as well as medically informed and effective health care, can be found at the Hennepin County Medical Center in Minneapolis. The influx of immigrants and refugees to that city has become so vast and variegated that the center is spending \$3 million dollars a year on interpreters fluent in 50 languages to communicate with their foreign-born patients. A New York Times article about Hennepin reported that many of the patients whom they are treating "arrive with health problems seldom seen in this country ... and unusually high levels of emotional trauma and stress": ${ }^{11}$

Over time, ... some develop Western aliments, too, like obesity, diabetes and heart disease, and yet they often question the unfamiliar lifelong 
treatments these chronic diseases need. Some also resist conventional medical wisdom forcing change on the hospital. The objections of Somali women to having babies delivered by male doctors [for example] has led Hennepin ... to develop an obstetrical staff made up almost entirely of women. Doctors here say that for many of these newcomers, the most common health problems, and the hardest to treat, lie at the blurry line between body and mind, where emotional scars from troubled pasts may surface as physical illness, pain and depression. ${ }^{12}$

There is still another respect in which the field of bioethics has turned its gaze away from social and cultural factors that we find objectionable. To a significant degree, its concentration on ethical concomitants of biomedical advance and on research ethics has diverted its attention from issues such as the adverse effects of poverty and social deprivation on health, national and international inequities in access to health care, and the consequences of the emergence and reemergence of infectious diseases, especially in developing countries. The burning moral questions of social justice that these conditions involve are marginalized by the inclination of many bioethicists to define them as social, economic, and political rather than ethical-another dichotomy that we consider unacceptable. And we are struck by the fact that the roster of what are defined as the chief bioethical issues in most of the countries to which bioethics has traveled does not differ substantially from those around which U.S. bioethics is centered.

Our criticisms of bioethics have always been accompanied by our affirmation that it is because we take bioethics seriously, and consider its national and international development to be a phenomenon of considerable sociological as well as intellectual and moral significance, that we are concerned about its social and cultural deficiencies. Our critique has elicited a wide gamut of reactions from the U.S. bioethics community, including perplexity, ambivalence, indifference, defensiveness, indignation, and also some appreciation and commendation. We have not been expelled from bioethics circles; we are considered to belong to the founding generations of the field; and one of us has even been accorded a Lifetime Achievement Award from the American Society for Bioethics and Humanities. ${ }^{13}$ Nevertheless, on the American bioethics scene we have not observed any promising signs of a collective will to undertake the intellectual work that we believe is needed to make the overarching conceptual framework and the ethos of the field more knowledgeably responsive to social and cultural context and diversity. Perhaps the conviction and initiative that are necessary to bring this about will have to-and ought to-come from some of the other societies in which bioethics is now flourishing.

\section{Notes}

1. Fox RC, Swazey JP. Observing Bioethics. New York: Oxford University Press; 2008. See especially Chapter 6, "Thinking Socially and Culturally in Bioethics," and Chapter 8, "Bioethics Circles the Globe."

2. Gustafson JM. Moral discourse about medicine: A variety of forms. Journal of Medicine and Philosophy 1990;15(2):127.

3. Beauchamp TL, Childress JF. Principles of Biomedical Ethics. New York: Oxford University Press; 1979.

4. Beauchamp TL, Childress JF. Principles of Biomedical Ethics, 5th ed. New York: Oxford University Press; 2001:3-5. See also Beauchamp TL. A defense of the common morality. Is There a Common Morality? Special issue. Kennedy Institute of Ethics Journal 2003;13(3):259-74. 


\section{Guest Editorial}

5. See, for example, Macklin R. Against Relativism: Cultural Diversity and the Search for Ethical Universals. New York: Oxford University Press; 1999.

6. The "ability to attend to the universal without abandoning the particular" is a phrase applied by medieval historian David Nirenberg to the thought of philosopher Hans Jonas in an essay-review ("Choosing Life") that he wrote about two of Jonas's books in the November 8, 2008 issue of The New Republic (pp. 39-43, at p. 43).

7. Bourdieu P. Uniting to better dominate. Items and Issues 2001;2(3-4):3.

8. LaFleur W, personal communication, June 3, 2007. La Fleur's exact statement was: "Bioethics has become international without becoming internationalized."

9. See note 1, Fox, Swazey 2008:226.

10. See Geertz C. Religion as a cultural system In: Geertz C. The Interpretation of Cultures: Selected Essays. New York: Basic Books; 1973, especially pp. 98-108.

11. Grady D. Foreign ways and war scars test hospital. New York Times 2009 Mar 28:A1.

12. See note 11, Grady 2009:A1.

13. Renée Fox, in October 2007. 